Send your letters to the Editor,

British Dental Journal,

64 Wimpole Street

London

W1G 8YS

Email bdj@bda.org

Priority will be given to letters less than 500 words long.

Authors must sign the letter, which

may be edited for reasons of space.

\section{BACK DOOR DENTISTRY}

Sir, some while ago I performed a clearance for a patient. I asked where he was to have his dentures made and he informed me that a technician he knew was going to make them. I enquired who and it was apparent that he was not registered to do this work. After a long while, having contacted the GDC, I have been informed that although the technician is not registered to make dentures they are not going to take any further action.

What does this say about the GDC who is supposed to be 'protecting patients and regulating the dental team'? What indeed is the point of registering everyone who goes through the back door of a dental surgery and then not acting when the rules are broken?

S. C. Bazlinton , Essex

Editor-in-Chief's note: Readers are informed that we asked the GDC if they wished to respond to this letter but were told that they were unable to respond unless details of the person working illegally were disclosed, but even then their response would be subject to their disclosure policy.

DOI: $10.1038 / s j . b d j .2009 .1140$

\section{PERSPECTIVE ON DENTISTRY}

Sir, I would like to add further comment to P. Ramsay-Baggs' letter (BDJ 2009; 207: 191) regarding the management of emergencies in practice. The maxillofacial hospital post was highlighted as being a good source of training and experience for such events - with management of the sublingual haematoma and risk of airway compromise (BDJ 2009; 206: 449) being used as the example.

Yes, I understand the anxiety that some of our seniors within the deaneries have regarding 'dental' SHOs being responsible for patients (who are often quite unwell) on the ward, in AftE etc. May I raise the point that this has been the successful system for years in many institutions.

Indeed, I am not suggesting that following employment as a maxillofacial SHO, the individual has acquired the skill set of a registrar or consultant. If anything, the clinician has learnt to identify the potential clinical emergency, determine its urgency, make the appropriate referral and provide interim care/ relief if within his/her remit. Surely, this can only serve to improve quality and consistency of care in both primary and secondary sectors?

As a recent graduate myself (2007), I have just completed six months as a maxillofacial SHO in a London teaching hospital following vocational training. I gained much exposure to a variety of hard and soft tissue facial and dentoalveolar trauma and emergency (often affecting the medically compromised patient) in a supported, safe environment. The time spent 'on call' was invaluable in developing diagnostic and management skills. One learns to prioritise clinical need, refine record keeping and surgical skills and liaise confidently with seniors and colleagues from other specialities.

I wholeheartedly agree with P. Ramsay-Baggs' suggestion of 'on call' being part of a compulsory F2 post and would go one step further in proposing a minimum six-month maxillofacial stint as part of foundation training. SHOs would only feel overwhelmed by, or incapable of, doing the job if they were poorly selected at interview and/or not offered sufficient support and teaching during their post.
I am yet to meet a colleague who regrets doing such a post. For me personally, it gave me perspective on dentistry in the 'wider context' of medicine, general confidence in 'people management' and sheer physical stamina!

M. C. de Souza, By email

DOI: 10.1038/sj.bdj.2009.1141

\section{CLARIFYING POINTS}

Sir, we wish to thank Dr Short for her letter and would like to clarify a few points made about our Cochrane review. ${ }^{1}$

Firstly, the review does not suggest that extracting primary teeth is unhelpful, it does, however, point out to clinicians that the practice of extracting primary canines to aid the eruption of palatally displaced canines is not evidence-based. The study by Ericson and Kurol, from which the Royal College Guidelines are based, is a cohort study with no control., ${ }^{2,3}$

Dr Short commented that neither their study or the study by Ericson and Kurol were referenced; I suggest she reads the full review as both are quoted and referenced. With regard to the accompanying photograph of an infant shown in the news bulletin ( $B D J$ 2009; 206: 454) we agree this was inappropriate; the authors of the review were not involved in this publication. The full review states ' $80 \%$ of participants should be aged between ten and 13 years' and intervention prior to age ten is contra-indicated.

The example provided by $\mathrm{Dr}$ Short of a patient with bilaterally impacted canines is of interest, however, it is a 'case report' and therefore does not add to our evidence base. We appreciate that clinical experience is of great value, expert opinion and case reports help us 